\title{
IMAGENS DA MEMÓRIA DA FACULDADE DE LETRAS
}

\author{
Rachel Esteves Lima
}

UFBA

\section{DA COLEÇÃO DE CACOS}

Tenho diante de mim um álbum de figurinhas. Através dele, fragmentos da história da UFMG são-me sensorialmente transmitidos. Cada um desses fragmentos tem que passar primeiro pelo prazer tátil de colar os cromos em seu devido lugar. Só com esse gesto a imagem se ligará à legenda que a aguarda, para que seja possível compor uma narrativa visual dos 80 anos da Universidade, completados em 2007. O álbum, presenteado por um amigo que conhece meu gosto pela história das instituições de ensino superior, já veio acompanhado das 241 figurinhas que só agora, diante do convite para participar da publicação em homenagem aos 40 anos da Faculdade de Letras, 35 anos da criação do curso de Pós-Graduação em Letras e 10 anos de início do Programa de Pós-Graduação em Letras: Estudos Literários, ponho-me a colar, uma vez que elas aguardavam um acontecimento para despertar minhas lembranças. Retorno à alegria da velha brincadeira infantil e, o que é melhor, dessa vez vejo eliminada a insatisfação que sempre me acompanhava quando, ainda criança, passava meses e meses montando uma coleção que nunca se completava. De qualquer forma, opto por não ordenar as figurinhas em ordem numérica para facilitar o trabalho. Prefiro o vai-e-vem das páginas, adiando ao máximo o momento em que verei as várias imagens se unirem em mosaico. Tampouco conseguiria recuperar a linearidade do fluxo do tempo se a colagem fosse sequencial. A lógica constelar do álbum, inspirada pelo poema Coleção de cacos, de Drummond, promove a "superposição do tempo", mesclando o passado e o presente da Universidade, aqui reconfigurados através de todo um coletivo que atuou para the dar a forma com que hoje ela se apresenta: professores, alunos, funcionários, operários, prédios (novos e antigos), equipamentos, acervos, monumentos, cartazes e até árvores e animais compõem cenas que me são mais ou menos familiares.

Aos poucos, vou construindo a minha "cacografia" particular: relembro fatos e eventos dos quais também participei, reconheço lugares, pessoas, paisagens, que fazem parte de minha memória afetiva e que me remetem a dois tempos, vividos em duas escolas distintas: a Faculdade de Ciências Econômicas e a Faculdade de Letras. Na segunda, descobri a tempo o lugar que queria ocupar no mundo. Por isso, as imagens alusivas à FALE me emocionam muito mais e me remetem a uma história que, principalmente no que se refere ao campo da Literatura, um dia, a meu modo, também tentei contar. ${ }^{1}$ É a essa narrativa que recorro agora, esperando contribuir para prestar uma justa homenagem a todos os que participaram do processo de construção dessa comunidade.

${ }^{1}$ LIMA. A crítica literária na universidade brasileira. 


\section{DA BUSCA PELA ORIGEM}

A Universidade de Minas Gerais foi fundada, em 1927, a partir do agrupamento de cinco faculdades de cunho profissionalizante. A criação da Faculdade de Filosofia de Minas Gerais iria ocorrer bem mais tarde, no final da década de 1930, seguindo o impulso gerado com a fundação da Faculdade Nacional de Filosofia no seio da Universidade do Brasil, modelo a ser seguido por todas as outras. Até essa época, o ensino superior na capital mineira consistia nas escolas agrupadas pela Universidade, no Conservatório Mineiro de Música e nas escolas isoladas de Arquitetura, de Veterinária e de Enfermagem, mais tarde absorvidas pela UMG. ${ }^{2}$ Os Seminários do Caraça, de Mariana e de Diamantina apresentavam-se em todo o estado como os espaços privilegiados para a transmissão da tradição filosófica e a formação de caráter humanista, enquanto que a orientação técnico-científica cabia à Escola de Minas de Ouro Preto. O ensino secundário da capital apresentava, por sua vez, uma demanda crescente, em virtude da expansão demográfica alcançada pela cidade nas duas últimas décadas. Os colégios, de um modo geral, ressentiam-se da falta de preparo para o magistério.

Insatisfeito com o contexto acima descrito, um grupo de professores do Colégio Marconi vinha desde o início da década de 1930 acalentando a idéia da fundação de uma Faculdade de Filosofia em Belo Horizonte. Geralmente detentores de uma formação humanista, esses professores ansiavam por uma instituição que lhes garantisse um espaço de desenvolvimento de um saber "desinteressado", a par que estavam sobre os movimentos de renovação no campo educacional. Dentre eles destacava-se o Prof. Arthur Versiani Velloso, que, em 1936, manteve contatos com o filósofo Émile Brehier, da Sorbonne, que aqui se encontrava a trabalho. Velloso lhe expôs o plano da Escola de Altos Estudos que o grupo buscava fundar, acompanhando-o na visita ao Caraça e à Escola de Minas de Ouro Preto e, em correspondência datada de 13 de abril de 1936, Bréhier forneceu a Velloso informações sobre a organização do ensino da filosofia na França, de modo a subsidiar a organização da escola por ele idealizada.

Com a instituição da Faculdade Nacional de Filosofia como núcleo da Universidade do Brasil e a outorga de um modelo a ser seguido por todas as outras faculdades congêneres, os professores vislumbraram a oportunidade de tornar realidade o seu projeto. Além do Prof. Velloso, participavam desse grupo os professores Braz Pellegrino, Pe. Clóvis de Souza e Silva, José Lourenço de Oliveira, Guilhermino César, Orlando de Carvalho, Nivaldo Reis, Mário Casassanta e o diretor do Colégio Marconi, Vincenzo Spinelli. Detonado, o movimento pela criação da nova faculdade passou a contar com a adesão dos principais nomes da intelectualidade local.

À Faculdade de Filosofia de Minas Gerais competiriam os mesmos objetivos traçados pela Faculdade Nacional de Filosofia da Universidade do Brasil. Entretanto, ela viria a se constituir fora da estrutura da Universidade de Minas Gerais, como uma unidade isolada, de caráter privado. Tal fato é creditado à falta de recursos financeiros da

${ }^{2}$ HADDAD. Faculdade de Filosofia de Minas Gerais; raízes da idéia de Universidade na UMG. Todas as referências à criação e institucionalização da Faculdade de Filosofia de Minas Gerais foram retiradas desse trabalho. 
Universidade para custear mais uma escola e ao preconceito de que foi alvo, em virtude do espírito conservador dos mineiros, que viam com desconfiança uma escola voltada para a filosofia e para a pesquisa da ciência pura e não para as profissões tradicionais.

A nova faculdade foi fundada em 21 de abril de 1939, contando com os recursos materiais e financeiros fornecidos pelo Instituto Ítalo-Mineiro Guglielmo Marconi, que cederia por trinta anos as instalações, o mobiliário e o equipamento necessários ao seu funcionamento. Apoiando a Faculdade de Filosofia, a Casa d'Itália cumpria o objetivo que se havia proposto, de auxiliar na divulgação dos princípios ideológicos fascistas. Foram promovidos diversos eventos com a participação da Faculdade e da Casa d'Itália, em que se conjugavam as manifestações da doutrina católica e do regime fascista.

Se a ligação com as instituições italianas está na origem da Faculdade de Filosofia, paradoxalmente essa mesma ligação iria dificultar o credenciamento de seus cursos. A simpatia inicialmente desferida pelo Governo Federal ao fascismo seria substituída por atitudes de franca hostilidade, quando o Brasil colocou-se ao lado dos países aliados. Tal fato levaria à criação de entraves burocráticos que impediram até o final do ano de 1940 o funcionamento da Faculdade. Finalmente, em novembro desse ano foi concedida a autorização prévia para o funcionamento dos cursos de Filosofia, Matemática, Geografia e História, Ciências Sociais, Letras Neolatinas e Letras Clássicas, que se iniciaram em 1941. Os cursos de Física, Química, História Natural, Letras Anglo-Germânicas, Pedagogia e Didática, que ainda faltavam para completar a estrutura da FNFi, foram iniciados em 1942 sem credenciamento e assim continuariam até 1947.

O rompimento das relações entre o Brasil e os países do Eixo, em março de 1942, afetaria a situação da Faculdade de Filosofia, até então dependente do apoio logístico das instituições italianas instaladas em Belo Horizonte. Desde janeiro daquele ano já estavam sendo efetuadas gestões junto ao Governo Estadual no sentido de obter a sua colaboração para que a Faculdade fosse transferida para um estabelecimento estadual. Em abril, foi concedida permissão para que a Faculdade de Filosofia se transferisse, sem qualquer ônus financeiro, para as instalações da Escola Normal Modelo (atual Instituto de Educação).

Começaria, então, a luta pelo reconhecimento dos cursos da Faculdade. Os que possuíam autorização prévia para funcionamento foram reconhecidos em março de 1946 e os demais só foram efetivados em outubro de 1947. Regularizada a sua situação legal, a Faculdade de Filosofia pôde contar com maior credibilidade junto à comunidade e os seus fundadores passariam a envidar esforços no sentido de fortalecê-la financeiramente. Em dezembro de 1946, o Governo Estadual autorizou a concessão de um generoso auxílio financeiro para a constituição do patrimônio da Faculdade, o que facilitaria a sua incorporação pela Universidade de Minas Gerais, ocorrida em novembro de 1948.

A absorção da Faculdade de Filosofia pela UMG, acreditavam os seus idealizadores, viria corrigir uma deficiência de origem daquela universidade: a falta de integração entre seus cursos, conforme se depreende do depoimento de Pedro Parafita de Bessa:

[...] a Faculdade de Filosofia teria o papel de transformar a Universidade Brasileira, que a gente, de brincadeira, a respeito da nossa, chamava de Escolas Reunidas Mendes Pimentel; aqui era folclore chamar a Universidade de Escolas Reunidas Mendes Pimentel, porque ele tinha sido o primeiro reitor e porque as escolas eram totalmente independentes; 
o reitor quase que só tinha um papel de representação social da Universidade. A Faculdade criaria duas coisas: primeiro ela criaria o espírito universitário e não o espírito profissional; e, em segundo lugar, ela seria a semente de unificação da Universidade em uma instituição orgânica que fosse universidade mesmo, e não escolas reunidas. ${ }^{3}$

Os educadores mineiros também iriam defender como função primordial da instituição a pesquisa e a busca de um saber desinteressado, de acordo com as diretrizes traçadas para as congêneres paulista e carioca.

Vários obstáculos se contraporiam, entretanto, a esse projeto. Também em Belo Horizonte os cursos oferecidos pela Faculdade de Filosofia não atrairiam muitos alunos. Para garantir o preenchimento das vagas organizaram-se campanhas de divulgação dos cursos junto aos estudantes de nível secundário e instituiu-se um prêmio que consistia em garantir a gratuidade do curso escolhido ao aluno que se destacasse "de modo excepcionalmente brilhante" ao término do segundo grau.

As dificuldades relacionadas às instalações físicas e à criação e manutenção de laboratórios indispensáveis à pesquisa na seção de Ciências se fizeram sentir de imediato. Apenas com a federalização da UMG, a Faculdade poderia contar com os recursos minimamente necessários à viabilização de sua proposta. Em 1952, a Faculdade passou a contar com uma sede própria, transferindo-se para o Edifício Acaiaca e podendo, enfim, contar com uma infra-estrutura modesta, porém compatível com os seus objetivos. ${ }^{4}$ Antes disso, a pesquisa na FaFi praticamente se restringia ao Instituto de Biologia, criado com o empenho do Prof. Braz Pellegrino e que contou, pioneiramente, com a atuação de um cientista e pesquisador em regime de tempo integral, o Prof. Giorgio Schreiber. Nas demais áreas, o desenvolvimento da pesquisa se dava lentamente até a década de 1950, quando se deflagraria uma política especialmente voltada para esse fim.

A Faculdade de Filosofia de Minas Gerais nasce, pois, do esforço de um grupo de professores e não do empenho de uma elite econômica esclarecida, como ocorrera com a Universidade de São Paulo (USP), ou sob o patrocínio do Governo Federal, como era o caso da Faculdade Nacional de Filosofia (FNFi). Não pôde contar em seus quadros com professores estrangeiros que favorecessem a assimilação de uma cultura voltada para a pesquisa. Ao contrário, o seu corpo docente foi constituído precariamente. Maria de Lourdes Haddad esclarece que a maior parte $(66 \%)$ dos professores catedráticos fundadores da FaFi-MG provinha de cursos profissionalizantes, com predominância para a área de Direito $(32 \%)$, e que sete professores (14\% do total) eram autodidatas, não possuindo nenhum diploma de curso superior. Tal fato viria confirmar o panorama cultural descrito por Maria Arminda do Nascimento Arruda como um empecilho à formação de uma comunidade universitária que se pautasse por uma atividade crítica autônoma: "Em suma, no panorama belorizontino estava indelevelmente inscrito o domínio da cultura tradicional e esta era dinâmica, corroborada numa ambiência beletrista e jurisdicista". ${ }^{5}$

\footnotetext{
${ }^{3}$ Apud HADDAD. Faculdade de Filosofia de Minas Gerais; raízes da idéia de universidade na UMG, p. 121. ${ }^{4}$ Sobre o período em que a FAFi funcionou no Edifício Acaiaca, conferir o artigode Silviano Santiago "Sorriso franco no rostinho encantador", publicado no número 1 da revista Diversa.

${ }^{5}$ ARRUDA. História das Ciências Sociais no Brasil, v. 1, p. 242.
} 
Vários professores da Faculdade de Filosofia pertenciam a um universo intelectual no qual se destacavam enquanto jornalistas, escritores e/ou funcionários públicos. Dentre eles, podem ser citados: Emílio Moura (escritor), Eduardo Frieiro (funcionário da Imprensa Oficial, escritor e jornalista), Guilhermino César (escritor, jornalista e chefe de gabinete do Chefe de Polícia) e Cyro dos Anjos (escritor e funcionário público).

Logo após a sua criação, a FaFi-MG passou a sofrer uma grande rotatividade dos professores catedráticos, o que acabou gerando um clima de insegurança quanto ao seu destino. Os professores normalmente mantinham atividades paralelas das quais dependiam para o seu sustento, uma vez que a remuneração na cátedra ou era inexistente ou era praticamente simbólica. A sobrevivência da Faculdade seria garantida por um grupo de professores que se empenhou na luta pela sua manutenção e que, valendo-se de um certo grau de influência cultural e política, conseguiu arrebanhar no ainda provinciano cenário cultural os catedráticos das diversas seções da FaFi e garantir junto ao Governo Estadual a sua incorporação pela Universidade de Minas Gerais.

A falta de tradição de pesquisa do corpo docente seria um dos principais empecilhos à difusão de um novo modelo universitário. Alguns professores, conscientes das limitações a que estavam sujeitos, com uma formação eminentemente teórica, assumiriam o papel de "formadores de uma nova geração de profissionais mais competentes teoricamente e com melhor formação técnica do que eles, em atividades de pesquisa". ${ }^{6}$ Para tanto, valeria o seu empenho no sentido de proporcionar condições para que os alunos pudessem ter contato com outros centros de pesquisa. Nesse sentido, ressalta-se o papel desempenhado pelo Prof. Velloso, que, segundo Francisco Iglésias e Francisco Magalhães Gomes, era o "elemento aglutinador" da Faculdade, o seu "verdadeiro criador".? Sua ação não se limitava à seção de Filosofia, uma vez que, de acordo com Pedro P. Bessa, ele se preocupava em cooperar com as demais, buscando sempre obter recursos que possibilitassem aos estudantes a ampliação de suas oportunidades:

O Velloso era uma pessoa altamente inspiradora de novos rumos: o que se devia fazer, o que a Faculdade podia vir a ser no futuro... Ele achava o nosso meio muito limitado, e que deveria ser feito um grande esforço no sentido de mandar gente estudar fora, arranjar bolsas, facilitar, apoiar, influenciar, pedir, exigir, gritar o que fosse necessário para conseguir bolsas. O importante é que pessoas da Universidade, de todas as áreas, fossem estudar em outros lugares, Rio, São Paulo, no exterior, em qualquer lugar, desde que saíssem daqui, o que sempre arejaria um pouco, traria novas idéias de outros grupos, com outras preocupações. ${ }^{8}$

Não obstante todas as dificuldades encontradas, são comuns os depoimentos em que se valoriza o intercâmbio de experiências entre estudantes de cursos completamente diferentes e que, convivendo num mesmo espaço, participariam do aprendizado de uma postura intelectual em que se privilegiava a formação humanista aliada à investigação científica.

\footnotetext{
${ }^{6}$ HADDAD. Faculdade de Filosofia de Minas Gerais; raízes da idéia de universidade na UMG, p. 130. ${ }^{7}$ Apud HADDAD. Faculdade de Filosofia de Minas Gerais; raízes da idéia de universidade na UMG, p. 118. ${ }^{8}$ Apud HADDAD. Faculdade de Filosofia de Minas Gerais; raízes da idéia de universidade na UMG, p. 131. Conferir também o depoimento da Profa. Ângela Vaz Leão, em entrevista concedida a Eneida Maria de Souza e Rachel Esteves Lima (DUARTE et al. Para sempre em mim, p. 506-507, reproduzido neste número de Aletria, p. 11-37.)
} 
A federalização da Universidade de Minas Gerais, em 1949, viria consolidar a Faculdade de Filosofia, que a partir de então passaria a contar com mais recursos para o desenvolvimento de seus cursos. O grande impulso no que se refere à pesquisa só seria dado, entretanto, pela criação dos órgãos de fomento, já na década de 1950, gerando condições para que uma segunda geração daquela faculdade tentasse cumprir o objetivo que se propunha.

\section{DA CRIAÇÃO DOS PROGRAMAS DE PÓS-GRADUAÇÃO}

Em Minas Gerais, a imposição da mentalidade especializante demorou um pouco a se consolidar. Os professores da Faculdade de Filosofia partilhavam uma concepção humanista do ensino e mantiveram, durante muito tempo, a tradição do palanque. Como praticamente não contou com estrangeiros em seu corpo docente, a Faculdade de Filosofia teve que lidar com o autodidatismo de seus professores, que buscaram, entretanto, incentivar os alunos a completar a sua formação no exterior. A USP também se tornou uma referência fundamental para os docentes de algumas seções, principalmente da área de Ciências, que procuravam se matricular nos cursos de especialização daquela universidade. ${ }^{9}$ Mesmo com as dificuldades decorrentes dessa situação, os professores formados pela Faculdade passavam a se destacar em função de sua prática pedagógica, contribuindo na divulgação do curso junto aos alunos do nível secundário.

$\mathrm{Na}$ área de Literatura predominou, durante muito tempo, a visão tradicional, repassada pelas grandes sínteses historicistas baseadas em informações provenientes da História e da Economia. O Prof. Guilhermino César, titular da cadeira de Literatura Brasileira, reconhece, em depoimento ao projeto "Memória de Letras', que o curso não era muito teórico e que suas exposições eram fundamentadas em obras que procuravam refletir sobre a história brasileira. A ênfase só começou a recair no trabalho teórico a partir do início da década de 1960, com a criação da disciplina Teoria da Literatura, ministrada inicialmente por Maria Luiza Ramos, ex-aluna do curso de Letras da Faculdade de Filosofia da UMG. Através de um esforço ainda autodidático, a professora contribuiu para a renovação dos estudos literários, tanto em Minas Gerais quanto no Brasil, com a publicação de seu livro Fenomenologia da obra literária, voltado para a fundamentação teórica indispensável à análise intrínseca do texto. ${ }^{10}$

No que se refere à pesquisa universitária, a Reforma de 1968 procurou retomar o processo de incentivo ao seu desenvolvimento, iniciado na década de 1950 com a criação da CAPES e do CNPq. Com a Reforma, foram reformulados os órgãos de incentivo à pesquisa e estipuladas, pelo Parecer no 77/69 do MEC, as regras que definiam as condições para o credenciamento dos cursos de pós-graduação e reforçavam a indissociabilidade entre as atividades de ensino e pesquisa.

No poder, o governo militar estrategicamente incorporou o planejamento das atividades de pesquisa ao seu projeto de modernização, datando da década de 1970 o I

\footnotetext{
${ }^{9}$ Cf. HADDAD. Faculdade de Filosofia de Minas Gerais; raízes da idéia de universidade na UMG, p. 132.

${ }^{10}$ Cf. RAMOS. Memorial.
} 
e o II Plano Básico de Desenvolvimento Científico e Tecnológico (PBDCT) e o I e II Planos Nacionais de Pós-Graduação. Através da definição das metas a serem atingidas por esses planos, procurava-se criar condições para a institucionalização dos cursos de pósgraduação no País, elevando-se os seus padrões de desempenho e garantindo a sua expansão. Como instrumentos para se atingir os objetivos traçados, citem-se a restrição à contratação de professores universitários não pós-graduados, o Programa Integrado de Capacitação Docente (PICD), que possibilitou o deslocamento remunerado de professores para o exterior e para os centros que já possuíam um sistema de pós-graduação estruturado, e a concessão de bolsas de estudo no País e no exterior.

Dessa forma, embora a maior parte dos recursos tenha sido destinada às áreas de Ciências Exatas e Biológicas, as Ciências Humanas também foram beneficiadas pela "relativa (e ilusória) abundância de recursos" 11 liberados para a capacitação dos professores até que a crise do País se agravasse, no início da década de 1980. Na área de Letras, podese dizer que a partir desse momento, com o retorno dos professores que foram se doutorar no exterior e a consolidação dos cursos das maiores capitais do País, a pós-graduação mostrou-se capaz de garantir a sua reprodução interna, sem maiores dificuldades.

O primeiro curso de pós-graduação em Letras a ser credenciado no Brasil, de acordo com as novas normas, foi o da Universidade Federal do Rio de Janeiro, em 1970. Sua estruturação obedeceu à concepção especializante defendida por Afrânio Coutinho. Na área de Ciência da Literatura, por exemplo, o curso foi dividido em 4 áreas de concentração, a saber: Teoria Literária, Literatura Comparada, Semiologia e Poética, o que demonstra um empenho em definir conceitualmente as diversas formas de abordagem da obra literária. De um modo geral, pode-se afirmar que o grande número de áreas oferecidas pela UFRJ constitui uma exceção no quadro geral da pós-graduação em Letras do País, justificada pelas dimensões da Faculdade de Letras daquela universidade. Nos cursos da PUC-RJ e da UFMG, sabe-se que houve a pretensão de se criar uma área de concentração voltada especificamente para a Teoria da Literatura, mas, certamente em decorrência de problemas estruturais dos cursos de Letras dessas universidades, apenas a de Literatura Brasileira foi, àquela época, credenciada. Já na USP, no que interessa a este trabalho, duas áreas de concentração tiveram autorizado o seu funcionamento: Literatura Brasileira e Teoria Literária/Literatura Comparada.

Ao se entrar em contato com a produção dos cursos de pós-graduação dessas unidades, percebe-se, entretanto, que a sua denominação não determina necessariamente o enfoque nelas predominante. Os cursos de Literatura Brasileira, por exemplo, podem apresentar um significativo investimento teórico, principalmente na década de 1970, quando a disciplina de Teoria Literária tornou-se, de modo geral, hegemônica nas Faculdades de Letras, por representar a possibilidade de se calcar o estudo literário sobre conceitos, princípios, categorias e métodos desenvolvidos segundo padrões "científicos". E o de Teoria pode, por sua vez, assumir uma perspectiva em que a análise teórica se subordine à explicação do texto literário.

${ }^{11}$ GUSSO, CÓRDOVA, LIMA. A pós-graduação na América Latina; o caso brasileiro, p. 199. 


\section{Da produção acadêmica da Pós-Graduação em Literatura}

O Programa de Pós-Graduação em Letras da UFMG iniciou-se, efetivamente, em 1973, com 4 áreas de concentração (Linguística, Língua Portuguesa, Literatura Brasileira e Inglês) e o curso de Doutorado em Literatura Comparada, em 1985. Com o crescimento do Programa, optou-se, em 1998, pelo seu desmembramento em duas áreas: Estudos Linguísticos e Estudos Literários. O Programa de Pós-Graduação em Estudos Literários, único que interessa ao escopo deste trabalho, conta hoje com 4 áreas de concentração no Mestrado (Estudos Clássicos, Literatura Brasileira, Literaturas de Expressão Inglesa e Teoria da Literatura) e 2 no Doutorado (Literatura Brasileira e Literatura Comparada).

Uma rápida folheada na relação de dissertações e teses defendidas no curso de pós-graduação da Faculdade de Letras da UFMG, na área dos estudos literários, já nos permite definir o principal foco de interesse dos trabalhos ali desenvolvidos. Uma expressiva quantidade dedica-se à abordagem da literatura contemporânea, aqui considerada como aquela publicada a partir da década de 1960. Essa tendência pode ser percebida desde as primeiras dissertações ali produzidas. Alguns fatores nos levam a justificar esse fato.

Oferecendo, inicialmente, apenas o Mestrado em Literatura Brasileira (não me reporto, logicamente, à área de Linguística), o curso de pós-graduação da FALE-UFMG procurou cultivar nos alunos a preocupação em fundamentar teoricamente suas análises. Coube à disciplina de Teoria da Literatura, como se viu, renovar, no nível da graduação, os métodos historiográficos que persistiam até a década de 1970, em função da falta de tradição de pesquisa universitária na área de Letras da UFMG. Os professores autodidatas que estavam na origem do curso não possuíam a abertura necessária para o processo de especialização como nas outras universidades a que se refere este trabalho. Diante da obrigatoriedade da instituição da disciplina de Teoria da Literatura no nível da graduação, a responsabilidade por essa disciplina recaiu sobre a Profa. Maria Luiza Ramos. Sensível à carência de obras que colocassem à disposição do aluno as conquistas teóricas que vinham se processando na área de literatura nos Estados Unidos e na Europa, Maria Luiza Ramos procurou suprir essa lacuna, ao sistematizar em Fenomenologia da obra literária, publicada em 1969, os princípios teóricos da fenomenologia de Husserl e Ingarden, particularmente. O pioneirismo da Professora deve ser ainda mais valorizado, se considerarmos que o seu trabalho conseguiu romper com a perspectiva humanista predominante no meio universitário e nas obras publicadas sobre literatura no País, que, até aquele momento, se prendiam à perspectiva historiográfica.

Além de apresentar os princípios teóricos, a Fenomenologia procurava oferecer exercícios de leitura crítica, tomando como objeto de estudo obras de Carlos Drummond de Andrade, Manuel Bandeira, Jorge de Lima, Mário de Andrade, Cecília Meireles, João Cabral de Melo Neto, Henriqueta Lisboa, Emílio Moura, Luís Vilela e Guimarães Rosa. Como se vê, a autora mostrou-se também atualizada em relação à produção literária brasileira contemporânea à época do lançamento do livro. Sabe-se que o fato de os professores pioneiros da Faculdade de Filosofia serem, normalmente, escritores facilitou a inclusão de autores contemporâneos no currículo de Letras da UFMG. Ao contrário do que ocorreu na USP, por exemplo, onde apenas a partir da entrada de Antonio Candido, na década de 1960, passou-se a privilegiar o estudo do modernismo e a literatura 
contemporânea, ${ }^{12}$ no curso mineiro tal fato ocorria desde os anos 1940. Na escolha do corpus de seu trabalho, Maria Luiza Ramos dava continuidade, portanto, à tradição dessa universidade de se acompanhar de perto o presente. Não se deve igualmente esquecer que a literatura produzida a partir da década de 1920 adaptava-se melhor às análises imanentistas propostas pela ciência da literatura, que a professora ajudou a difundir.

A força da Teoria da Literatura na Faculdade de Letras da UFMG pode ser comprovada por uma consulta às pesquisas ali desenvolvidas, desde o início da pósgraduação. Nota-se, desde os primeiros trabalhos defendidos, uma preocupação em se aliar as teorias imanentistas à leitura contextualizada. Dois fatores explicam essa constatação: o primeiro diz respeito à influência exercida por uma outra linha de pesquisa, baseada no estudo sociológico da literatura e corporificada pelo trabalho de Letícia Malard. O segundo, refere-se ao estágio em que se encontrava a Teoria da Literatura quando foram defendidas, em 1978, as primeiras dissertações na UFMG. Naquele momento, a a-historicidade do estruturalismo já começava a ser minada pela difusão da obra de Mikhail Bakhtin, retomada e reatualizada por Julia Kristeva e Roland Barthes, e de autores pós-estruturalistas, como Foucault e Deleuze. ${ }^{13}$ Aqueles trabalhos se alimentaram, dessa maneira, da mélange desses autores com o estruturalismo antropológico de Lévi-Strauss e, algumas vezes, com teóricos sociológicos como Lukács, Goldmann, Gramsci e Antonio Candido.

As dissertações, até meados da década de 1980, normalmente partiam da abordagem das várias instâncias do discurso ou das relações intertextuais estabelecidas pela obra, seguindo a estratégia analítica da decomposição que caracterizou o enfoque que predominou em todo o país, na década de 1970 e começo da de 80. A transição para uma postura pós-moderna de interpretação literária pode ser situada a partir dos trabalhos defendidos em 1986 e 1987, que, tendo como objeto de estudo a poesia marginal e os romances documentais das décadas de 1960 a 80, procuravam questionar o preconceito com que essas obras vinham sendo recebidas pela crítica universitária. Os cursos ministrados por Lauro Belchior Mendes, interessado numa abordagem sociocrítica, muito contribuíram para a revitalização da leitura das obras consideradas engajadas. $O$ conceito de alegoria, tal como proposto por Walter Benjamin na sua análise do drama barroco e da obra de Baudelaire, ofereceu apoio teórico capaz de legitimar a escolha de uma literatura rotulada como neo-naturalista como tema das dissertações. Já as pesquisas que incorporavam a questão do retorno do sujeito sinalizavam uma nova forma de recorte do trabalho acadêmico, que seria consolidada com as teses que começaram, em 1989, a ser defendidas no curso de Doutorado em Literatura Comparada.

Como esse curso só foi criado em 1985, a maior parte dos professores que atuaram na pós-graduação da UFMG doutorou-se em outros centros de estudo. O Doutorado em Literatura Comparada pôde ser estruturado a partir do retorno de 6 professores, que, ao final da década de 70, procuraram se qualificar no exterior. Outros 7 doutoraram-

${ }^{12}$ Cf. CANDIDO, SCHWARZ. Antonio Candido Eु Roberto Schwarz: a homenagem na UNICAMP, p. 20.

${ }^{13}$ Deve-se ressaltar que as teorias estruturalistas e pós-estruturalistas foram difundidas na UFMG pela Profa. Eneida Maria de Souza, que cursara o Mestrado na PUC do Rio de Janeiro. 
se no Rio de Janeiro e em São Paulo. ${ }^{14}$ A formação diversificada desses professores fez com que o curso de pós-graduação pudesse constituir-se como um espaço de diálogo entre várias linhas de pesquisa diferentes. Tal fato justifica a grande heterogeneidade de enfoques, que vão da psicanálise e da semiologia ao movimento da desconstrução, que embasa os estudos da pós-modernidade, sem deixar de mencionar os resultados colhidos a partir da leitura sociológica e da pesquisa em fontes primárias.

Através do curso de Literatura Comparada, operou-se uma transformação no recorte dos trabalhos desenvolvidos até mesmo no Mestrado em Literatura Brasileira. Se, antes, a contextualização ocorria paralela à análise formal da obra estudada, a partir do Doutorado em Literatura Comparada, os detalhes formais foram colocados em segundo plano, buscando-se abrir espaço para que houvesse um diálogo entre contextos diferenciados, de forma a permitir que a energia, a força de uma obra, se manifestasse, no contato com outra. O fato de o curso congregar professores de áreas diferentes favoreceu a diversidade das abordagens, além de ter contribuído para ampliar a visão das manifestações culturais contemporâneas, em outros países, através dos cursos oferecidos pelos professores de literatura estrangeira.

O comparativismo, retomado a partir da proposta de Silviano Santiago, que rejeita a apologia do subdesenvolvimento alimentada pelas pesquisas de fontes e influências, assumiu na UFMG uma centralidade que não se observou nos cursos destinados a esse tipo de abordagem, na UFRJ e na USP. Como esse enfoque requer o estabelecimento de pontos de contato entre obras brasileiras e estrangeiras, sistemas semióticos ou campos diversos, a análise totalizante cedeu o lugar aos trabalhos temáticos, que não apresentam mais a pretensão de esgotar o significado das obras analisadas, mas se constituem como o resultado de uma atividade que se propõe ser considerada apenas como um "suplemento", um exercício de "sobreinterpretação." 15 O questionamento da objetividade científica e a consciência de que o saber é sempre fragmentário liberaram a crítica para assumir que sua tarefa se define como uma "arte combinatória", possibilitada pelo trânsito não apenas entre as esferas de saber legitimadas pelas instituições tradicionais, mas também entre as várias esferas cognitivas que constituem a vivência contemporânea.

O vigor das pesquisas transdisciplinares e dos temas que constituem a questão da pós-modernidade é acentuado nos trabalhos produzidos a partir do final da década de 1980. Deve-se ressaltar, aqui, a contribuição de Eneida Maria de Souza e de Wander Melo Miranda nesse processo, uma vez que é incontestável o esforço desenvolvido por esses professores para promover na pós-graduação a atualização teórica e o dinamismo necessário para reafirmar esse tipo de abordagem.

Inicialmente, os trabalhos orientados por Souza assumiam a perspectiva semiológica e psicanalítica, difundida por ela e por Vera Lúcia Andrade, nos cursos que as professoras ministraram, logo que retornaram da França. Esse approach teórico, que tem seu embrião nos estudos estruturalistas, embasa a maior parte das análises feministas e tem continuidade através da atuação de Ruth Silviano Brandão e Lúcia Castello Branco.

${ }^{14}$ Refiro-me, aqui, apenas aos professores que orientaram trabalhos nas áreas de Literatura (Literatura Brasileira, Teoria da Literatura e Literatura Comparada), que são objeto deste trabalho.

${ }^{15}$ ADORNO. Theodor Adorno, p. 168. 
As pesquisas sob supervisão de Eneida Maria de Souza encaminharam-se, posteriormente, para os estudos de outras minorias e para as relações inter-culturais; os orientados por Vera Andrade introduziram a questão da narrativa pós-moderna. O memorialismo foi o tema privilegiado pela orientação de Wander Melo Miranda, que dava, assim, continuidade à reflexão desenvolvida em sua tese de Doutorado, defendida na USP, na qual abordou comparativamente as obras de Graciliano Ramos e Silviano Santiago. Os estudos sobre o discurso da memória representam uma grande parcela das pesquisas desenvolvidas na UFMG, não apenas sob a orientação de Wander Miranda, mas também de outros professores.

As relações intersemióticas recebem uma atenção especial. Através da atuação de vários professores, dentre os quais citamos Vera Casa Nova, Letícia Malard, Wander Miranda, Lúcia Castelo Branco e Maria das Graças Paulino, as pesquisas que se dedicam a sistemas semiológicos diversos, como o jornalismo, o cinema, a arquitetura urbana, a pintura e o teatro, foram incentivadas. Também a literatura que trata das questões das minorias começou, a partir dos anos 1990, principalmente, a se mostrar presente nos estudos que se dedicam à mulher, ao negro, ao homossexual e aos imigrantes, orientados inicialmente por Eneida Maria de Souza, Ana Lúcia Gazolla e Maria Zilda Cury, professora que também introduziu na UFMG as pesquisas sobre fontes primárias.

A questão da dependência cultural foi atualizada pelos trabalhos que discorrem sobre a dominação pós-colonial e retomam a discussão sobre a nacionalidade e a identidade. Da mesma forma, as pesquisas sobre tradução, difundidas principalmente a partir do trabalho de Else Ribeiro Pires Vieira e Solange Ribeiro, vinculam-se a essa perspectiva, na medida em que abordam o papel exercido por esse tipo de mediação cultural para a definição da hegemonia de uma nação sobre outra.

A atenção aos temas da pós-modernidade fez com que persistisse, na UFMG, a tradição de abordagem da literatura contemporânea. Essa postura concretiza a ambição de se realizar um trabalho que atinja o estatuto de crítica cultural, em que as diversas manifestações artísticas são articuladas a uma leitura do espaço social em que são produzidas. A literatura comparada, dessa perspectiva, apresenta-se como uma metateoria, abandonando a perspectiva especializante e propondo o rompimento das fronteiras que procuravam definir a especificidade de cada campo de conhecimento. A atividade interdisciplinar constitui-se pela desterritorialização dos diversos campos do saber, em busca de um denominador comum, que Barthes anteriormente já havia sinalizado, ao propor o alargamento do conceito de "texto". ${ }^{16}$

\section{Do PASSADO AO PRESENTE}

Podemos situar no período que vai da segunda metade da década de 1980 a meados da década seguinte a emergência de novas subjetividades na cena cultural brasileira, e

\footnotetext{
${ }^{16}$ Para o autor, "o interdisciplinar, de que se fala muito, não consiste em confrontar disciplinas já constituídas (nenhuma delas, com efeito, consente em entregar-se. Para praticar o interdisciplinar, não basta escolher um "assunto" (um tema) e convocar à sua volta duas ou três ciências. O interdisciplinar consiste em criar um objeto novo, que não pertence a ninguém. O Texto é, creio, um desses objetos. (BARTHES. O rumor da língua, p. 81.)
} 
os trabalhos produzidos na pós-graduação, como se viu, vão reforçar a conexão entre as temáticas escolhidas para análise e tal contexto. Ao final dos anos 1980, começam os balanços sobre aquela que foi considerada a década perdida para a América Latina e as leituras formalistas cedem espaço às premissas teóricas dos Estudos Culturais, que vão subsidiar a leitura da produção simbólica das minorias, deslocando as margens para o centro do debate. A relativização do cânone, a politização da crítica frente ao contexto da globalização, assim como a hegemonia da perspectiva comparatista, são fenômenos simultâneos que vão alterar a configuração da área dos "estudos literários", que, a partir de então, passam a normalmente apresentar-se acompanhados pelo suplemento "e culturais". O relativo consenso antes existente no campo é abalado não apenas pela adoção dessas novas teorias, mas também pela emergência de um enorme contingente de pesquisadores, a partir da consolidação e reprodução dos cursos de pós-graduação. E é justamente essa capacidade de reprodução que vai ser colocada em causa no momento em que ocorre a aposentadoria de um número significativo de professores de renomada competência, acossados pela política universitária do governo Fernando Henrique Cardoso. Dessa difícil situação, percebe-se, hoje, que os Programas de Pós-Graduação da UFMG conseguiram se safar com relativa tranquilidade. Como lembra a ex-Diretora da Faculdade de Letras, Eliana Amarante Mendes, a FALE-UFMG conseguiu manter a participação de vários desses professores como colaboradores na Pós-Graduação e, ainda, renovar seu quadro docente "com pessoal altamente qualificado, altamente envolvido e comprometido com a instituição, e que, além do mais, tem a força e a alegria da juventude, o que representa para a Faculdade uma injeção de ânimo, um fortalecimento." 17

No Programa de Estudos Literários, em que se detém este ensaio, tal fortalecimento mostra-se visível na quantidade e na qualidade das teses e dissertações que têm sido ali defendidas. O nível de excelência atingido pelo Programa, expresso pela nota máxima da avaliação realizada pela CAPES, é hoje fato incontestável e a diversidade dos objetos de estudo e dos alinhamentos teóricos seguidos nos trabalhos evidencia que a terceira e, até mesmo, a quarta geração de professores da FALE, vem conseguindo corresponder e até mesmo superar as expectativas que os pioneiros da Faculdade de Filosofia depositavam no futuro. Mas, como fazer jus aos responsáveis por esses feitos aqui neste texto? Como prestar uma homenagem que seja capaz de não se esquecer de nenhum nome daqueles que, mesmo com as dificuldades aqui apontadas, contribuíram e contribuem para que o sonho se faça realidade? Após ter o trabalho de listar todas as teses e dissertações defendidas no âmbito do Programa, não apenas até 1995 (ano em que minha tese de doutorado se deteve), mas também nos últimos 10 anos, classificandoas por tema, chego à conclusão de que é impossível a construção de uma narrativa que possa fazer jus a cada um que esteve envolvido no trabalho até aqui realizado. Um trabalho pautado pela coexistência de uma pluralidade enorme de perspectivas teóricas e temáticas, que abarca dos estudos clássicos à análise dos produtos da cultura de massa, como os quadrinhos, o futebol, a ficção científica, etc.; da literatura canônica aos textos produzidos por aqueles antes relegados à margem do mundo acadêmico, como

${ }^{17}$ MENDES. Revisitações, p. 37. 
as mulheres, os indígenas, os afrodescendentes, os homossexuais, etc.; das matrizes culturais européias aos bens simbólicos criados no registro escrito ou oral de comunidades antes excluídas do universo literário, seja no Brasil, na América Latina, na África ou nos países pós-coloniais de língua inglesa; das diversas outras formas de arte, como o teatro, o cinema, a música, a arquitetura, ao questionamento da separação arte/vida operada pelas performances contemporâneas. Diante dessa diversidade, como sintetizar a colaboração de todos os que atuaram/atuam para a realização desse feito, sem operar nenhuma exclusão? Afinal, além dos professores, seria necessário nomear também os funcionários, responsáveis pelo trabalho burocrático, os operários que constroem as edificações, os servidores encarregados da limpeza, da preparação dos lanches, da segurança etc. E, além disso, seria também imprescindível recuperar detalhes da paisagem dos diversos lugares onde a Faculdade de Letras funcionou, do Colégio Marconi ao campus da Pampulha, com seus prédios, suas árvores, suas garças etc. Enfim, ao término de uma longa jornada, chego àquela constatação sempre reiterada por aqueles que estudam os discursos da memória: algo de incomensurável, de inenarrável, sempre escapará a qualquer relato. E talvez seja justamente por isso que, paradoxalmente, permaneça gravado em nós "o dever de não se esquecer de lembrar", ${ }^{18}$ de proceder à montagem de um mosaico com a nossa coleção de cacos. Seja através de um livro, uma tese, um texto ou um álbum de figurinhas...

A

\section{REFERÊNCIAS}

ADORNO, Theodor. O ensaio como forma. In: COHN, Gabriel (Org.). Theodor W. Adorno. Trad. Flávio R. Kothe, Aldo Onesti e Amélia Cohn. São Paulo: Ática, 1986. p.167-187. ARRUDA, Maria Arminda do Nascimento. A modernidade possível: cientistas e Ciências Sociais em Minas Gerais. In: MICELI (Org.). História das Ciências Sociais no Brasil. São Paulo: Vértice/Ed. Revista dos Tribunais/IDESP, 1989, v.1, p.234-315.

BARTHES, Roland. O rumor da língua. Trad. António Gonçalves. Lisboa: Edições 70, 1987. CANDIDO, Antonio; SCHWARZ, Roberto. A homenagem da UNICAMP. Campinas: Ed. UNICAMP, 1989.

GUSSO, Divonzir Arthur; CÓRDOVA, Rogério de Andrade; LIMA, Sérgio Vasconcellos. A pós-graduação na América Latina; o caso brasileiro. Brasília: CAPES, 1985.

HADDAD, Maria de Lourdes Amaral. Faculdade de Filosofia de Minas Gerais; raízes da idéia de universidade na UMG. 1988. Dissertação (Mestrado em Educação) - Faculdade de Educação da UFMG, Belo Horizonte, 1988.

LEÃO, Ângela Vaz. Entrevista concedida a Eneida Maria de Souza e Rachel Esteves Lima. In: DUARTE, Lélia Parreira (Coord.). Para sempre em mim. Belo Horizonte: CESPUC, 1999. p. 501-536.

${ }^{18}$ STARLING. 80 anos UFMG, p. 3. 
LIMA, Rachel Esteves. A crítica literária na universidade brasileira. 1997. Tese (Doutorado em Literatura Comparada) - Faculdade de Letras da UFMG, Belo Horizonte, 1997.

MENDES, Eliana Amarante de M. A Faculdade de Letras da UFMG, hoje e amanhã. In: MENDES, Eliana Amarante de Mendonça; OLIVEIRA, Paulo Motta; BENN-IBLER, Veronika (Org.). Revisitações: edição comemorativa 30 anos da Faculdade de Letras/UFMG. Belo Horizonte: UFMG/FALE, 1999. p. 35-38.

RAMOS, Maria Luiza. Memorial. 1981. Memorial (Titular em Teoria da Literatura) Faculdade de Letras da UFMG, Belo Horizonte, 1981.

SANTIAGO, Silviano. Sorriso franco no rostinho encantador. Diversa, Belo Horizonte, n. 11, p. 48-49, maio 2007.

STARLING, Heloisa (Coord.). 80 anos UFMG. Belo Horizonte: UFMG, p. 3. 